\section{Grapefruit juice and clopidogrel}

Bailey and colleagues ${ }^{1}$ are to be commended for highlighting the potential of many medications to interact with grapefruit. ${ }^{1}$ However, one medication on their list (Table $1^{1}$ ) deserves closer scrutiny.

At first glance, clopidogrel seems to fit the criteria of a medication that is a known substrate of CYP3A4 with low total bioavailability, but on closer examination the issue is less clear.

First, clopidogrel is a prodrug that needs to be metabolized to its active form. ${ }^{2}$ Therefore, it is the only medication listed in Table $1^{1}$ whose interaction with grapefruit via CYP3A4 may lead to a loss of efficacy instead of toxicity (this was correctly stated in Table $1^{1}$ ). However, the biotransformation of clopidogrel to its active form is a two-step process involving multiple CYP isoenzymes. Only in the second step in the process is CYP3A4 involved. ${ }^{3}$ Whether intestinal CYP3A4 (as opposed to hepatic CYP3A4) is even involved in this second step is unclear.

Second, the enzyme that is primarily responsible for the low bioavailability of clopidogrel is not a cytochrome P450 enzyme at all. Instead, $85 \%$ of clopidogrel is metabolized to an inactive compound through esterase enzymes. ${ }^{2}$ Interestingly, some suggest that grapefruit juice may inhibit intestinal esterase enzymes. ${ }^{4}$ If this were the case, grapefruit may increase the amount of parent drug available to be converted to its active form, which could lead to increased antiplatelet effect. Therefore, given the complex metabolic pathway of clopidogrel, what, if any, effect grapefruit would have on pharmacokinetics or pharmacodynamics of this agent is not clear. A randomized study examining the effect of grapefruit juice on the antiplatelet activity of clopidogrel will hopefully shed more light on this issue (ClinicalTrials.gov: NCT00817999).

\section{Mark H. Friesen BSc (Pharm) MSc Pharm D}

Clinical pharmacist, Winnipeg Regional Health Authority, Winnipeg, Man.

\section{References}

1. Bailey DG, Dresser G, Arnold JMO. Grapefruitmedication interactions: Forbidden fruit or avoidable consequences? CMAJ 2013;185:309-16.

2. Floyd CN, Passacquale G, Ferro A. Comparative pharmacokinetics and pharmacodynamics of platelet adenosine diphosphate receptor antagonists and their clinical implications. Clin Pharmacokinet 2012;51:429-42.

3. Kazui M, Nishiya $Y$, Ishizuka $T$, et al. Identification of the human cytochrome P450 enzymes involved in the two oxidative steps in the bioactivation of clopidogrel to its pharmacologically active metabolite. Drug Metab Dispos 2010;38:92-9.

4. Liederer BM, Borchardt RT. Enzymes involved in the bioconversion of ester-based prodrugs. J Pharm Sci 2006;95:1177-95.

\section{CMAJ 2013. DOI:10.1503/cmaj.113-2126}

\section{The author responds}

Friesen ${ }^{1}$ has provided thoughtful comments about the "loss of efficacy" of clopidogrel from grapefruit interactions that was reported in our article. ${ }^{2}$ Because clopidogrel is commonly prescribed in Canada and is used to prevent common and serious thromboticmediated cardiovascular events, reduction in the effectiveness of clopidogrel has potentially broad and significant clinical consequences. ${ }^{3}$

Friesen correctly notes that clopidogrel requires metabolic conversion before it can exert an antiplatelet effect and that this entails multiple sequential bioactivation steps involving cytochrome P450 enzymes (CYPs). One of these CYPs is CYP3A4, which grapefruit is known to inactivate. Because erythromycin and troleandomycin (CYP3A4 inhibitors) decrease and rifampicin (CYP3A4 inducer) increases the clinical antiplatelet activity of clopidogrel, one could conclude that this enzyme plays a key role in the therapeutics of this drug. ${ }^{4}$ These drugs most likely modulate the activity of CYP3A4 in both the small intestine and liver. Friesen ${ }^{1}$ rightly remarks that grapefruit primarily inactivates only intestinal CYP3A4. Moreover, he also puts forth the possibility that the low oral bioavailability of clopidogrel may not be from the action of CYP3A4, which is a fundamental characteristic for drugs that interact with grapefruit.
Friesen $^{1}$ mainly contends that whether grapefruit can attenuate the antiplatelet action of clopidogrel clinically is not currently clear. He cites the study "The Impact of Grapefruit Juice on the Response to Clopidogrel" found on ClinicalTrials.gov. ${ }^{1}$ Friesen ${ }^{1}$ believes that results from this study will be instrumental in deciding the relevance of this interaction.

The results of the completed ClinicalTrials.gov trial revealed that in the loading-dose phase, clopidogrel 300 $\mathrm{mg}$ with grapefruit juice versus water produced platelet inhibition of $23 \%$ compared with $41 \%$, respectively. In the maintenance phase, clopidogrel 75 $\mathrm{mg}$ with grapefruit juice versus water for 7 days resulted in inhibition of $25 \%$ compared with $59 \%$, respectively. Thus, our concern regarding "loss of efficacy" of clopidogrel from grapefruit interactions appears currently justified.

This information is not mentioned in the prescribing information for clopidogrel possibly because the present version, dated April 2012, of the prescribing information may have preceded completion of the trial in August 2012.

Of greater concern is that there is no indication of the effects of inhibition and induction of CYP3A4 caused by drugs or herbals - particularly St. John's wort - which have been known for several years.,

\section{David G. Bailey BScPhm PhD}

Scientist, Lawson Health Research Institute, London, Ont.

\section{References}

1. Friesen MH. Grapefruit juice and clopidogrel [letter]. CMAJ 2013;185:1066.

2. Bailey DG, Dresser G, Arnold JMO. Grapefruitmedication interactions: Forbidden fruit or avoidable consequences? CMAJ 2013;185:309-16.

3. Plavix [product monograph]. Laval (QC): SanofiAventis Canada; 2012. Available: www.bmscanada .ca/static/products/en/pm_pdf/Plavix_EN_PM.pdf (accessed 2013 Aug. 6)

4. Lau WC, Waskell LA, Watkins PB, et al. Atorvastatin reduces the ability of clopidogrel to inhibit platelet aggregation: a new drug-drug interaction. Circulation 2003;107:32-7.

5. Tirona RG, Bailey DG. Herbal product-drug interactions mediated by induction. Br J Clin Pharmacol 2006;61:677-81.

CMAJ 2013. DOI:10.1503/cmaj.113-2127 